\title{
Paradoxos pós-modernos na representação da modernidade e do modernismo: estudo de recursos expressivos da minissérie Um só Coração
}

Solange Wajnman Universidade Paulista/UNIP 


\section{Resumo}

Pretendemos demonstrar como o conjunto de elementos visuais da minissérie "Um só coração", ao percorrer a temática do moderno e do modernismo configura uma concepção histórica da identidade paulistana de maneira bastante paradoxal. Situada em uma condição atual de desenvolvimento tecnológico, com seu desenvolvimento e seus limites, a direção da minissérie da Rede Globo de Televisão opta e decide por certas representações visuais. Tratar-se-á então de demonstrar como a narrativa se encontra no paradoxo entre a tentativa de criar uma âncora temporal e espacial para a memória da identidade paulistana, ao mesmo tempo em que há a dissolução desta última em uma concepção abstrata e virtualizada.

\section{Palavras chave}

produção televisiva, teoria pós-moderna, modernidade, modernismo

\section{Abstract}

We have the objective of demonstrating how the visual elements of a group such as sceneries of the miniseries - "Um só coração" while going through the modern and the modernism thematic modes a historical conception of the 'paulistana' identity in a quite paradoxical. Situated in a current condition of technological development, with its development and its limits, the Rede Globo de Televisão (a television network) miniseries direction opts and decides for special visual representations. Then, the concern is to show how the narrative encounter the paradox between attempt to create a temporal and spatial anchor to the 'paulistana' identity recall, at the same time that there's a dissoluteness of that last in an abstract and virtualized conception.

\section{Key words}

television production, post-modern theory, modernity, modernism 


\section{Introdução}

T esteira das comemorações do IV centenário da cidade de São Paulo, a minissérie "Um só Coração", exibida pela Rede 1 Globo em 2004, apresentou a trajetória de São Paulo dentro de um panorama histórico (anos 20 a 50) e em que questões econômicas, estéticas, políticas e afetivas se articulavam.

Destacam-se aí algumas questões ligadas ao modernismo e a modernidade que se contextualizam em São Paulo e neste sentido, interessa-nos investigar como esta memória é trabalhada pela produção televisiva: cenário, figurino, iluminação e jogo de câmeras. Utilizando o referencial da discussão pós-moderna encontrada em alguns autores tais como Jameson(1999), Hutcheon (1991), Huyssen (2000), Barnard (2003) e Gastal (2006) problematizamos nos limites deste trabalho, alguns aspectos da representação da história paulistana, a saber: a visão de uma São Paulo moderna, a visão da vanguarda do movimento modernista, as questões da intertextualidade e das referências factuais.

Estando conscientes de que a direção da minissérie da Rede globo de televisão configura uma narrativa própria e elege uma concepção de mundo de modernidade e de modernismo do Brasil quando transmite a minissérie, optando e decidindo por certas representações de São Paulo e de sua memória, nos propomos a identificá-las a partir de configuração de seus recursos expressivos. Como seria esta representação? Apresentaria ela matizes da linearidade, representação fiel da história ou, ao contrário, adotararia ela a intertextualidade e estetização próprias às concepções de PósModernidade? Nossas reflexões nos conduzem ainda ao paradoxo 
contemporâneo próprio a várias produções da cultura midiática que, como esta minissérie, oscilam entre a tentativa de criar uma âncora espaço-temporal frente à globalização - protegendo a memória da identidade regional ou nacional - e a dissolução desta na glamorização dos estilos de época viabilizados pelos recursos tecnológicos.

Assim, dando primazia aos significantes expressos nos elementos materiais figurativos tais como cenários, figurinos e jogo videográfico e conforme orientações dos estudos recorrentes no campo das teorias das materialidades ${ }^{1}$ nos propomos a demonstrar as questões anunciadas.

\section{A figuração da minissérie e a representação de modernidade e modernismo}

Como mostra Pallotini (1998) o cenário, os ângulos tomados, os figurinos enriquecem uma narrativa na televisão. As câmeras ajudam a contar a história. Elas focalizam, recortam, aproximam, expõem, descrevem e deslocam a função narrativa para os atores, os figurinos e os cenários. Todos estes elementos são representações visuais de elementos psicológicos e sociológicos e servem para construir uma narrativa.

Assim, fruto de um desenvolvimento histórico dos recursos de produção, o texto de uma novela ou minissérie é hoje não somente expresso verbalmente mais principalmente narrado por um conjunto de elementos expressivos: jogo videográfico, objetos do cenário, indumentária. São todos os elementos que compõem as instâncias narrativas.

É possível identificar um amadurecimento dos recursos visuais nas telenovelas e minisséries. De qualquer maneira, de forma mais ou menos desenvolvida, a figuração que se realiza nos cenários e figurinos é uma maneira de dar forma visível a uma representação.

1. Filiamo-nos aqui aos estudos dedicados aos estudos da materialidade da comunicação e que se situam em uma discussão dentro de um campo não hermenêutico. Verificar os artigos de Gumbrecht (1998) em "Corpo e Forma". 
Assim como propõe Maria Cristina Volpi (2002) para o cinema, ao considerar que sistemas de figuração são imagens de objetos e espaços, pretendemos também pensá-los como linguagem visual da televisão, e, por conseguinte, como dispositivos expressivos a serviço do enunciado. Como a pesquisadora observa, os elementos da linguagem visual, ou seja, a linha, a cor, a forma, a textura, a escala, a dimensão e o movimento, aplicados aos objetos tridimensionais que compõem os sistemas de figuração, são utilizados a partir dos seus valores expressivos. Desta forma, estes elementos articulados num sistema topográfico, contribuem para a representação visual de aspectos psicológicos e sociológicos que servem para construir as personagens e os espaços. Associados aos elementos videográficos, tais como o enquadramento, a profundidade de campo, e a noção de "plano", os sistemas de figuração são, eles também, constituintes da linguagem televisiva.

No que diz respeito ao cenário podemos entendê-lo como a ilustração e figuração de elementos que se supõe existirem no universo dramático, os quais estão inscritos no espaço em três dimensões (Pavis, 1999). No contexto da produção audiovisual, a cenografia e os objetos de cena são uns dispositivos próprios para esclarecer o texto e a ação, para figurar uma situação de enunciação e para situar o sentido da ação num determinado espaço/tempo.

Na minissérie o moderno é apreendido algumas vezes por contrastes. Assim o velho mundo da oligarquia cafeeira representado pelo personagem do Coronel Totonho tem suas características expressas no cenário de sua imponente e taciturna residência. Os objetos são escuros e o espaço torna-se ainda mais sombrio já que evidenciado por um jogo de sombras e luzes. Alia-se a isto a figuração imponente do próprio coronel: as câmeras em contra plongée destacam sua pessoa em relação aos seus interlocutores, passando uma idéia de superioridade da sua figura. No mundo do moderno, onde as idéias progressistas são discutidas, as reuniões no casarão das lideranças da burguesia esclarecida, as luzes são claras, difundidas. De mesmo, no espaço de Tarsila do Amaral, expoente do movimento modernista, o cenário é muito claro, os objetos coloridos (suas telas e objetos), a iluminação suave. Vale dizer o mesmo para a seqüência 
dos modernistas que dançam e cantam em um ambiente em que a luz clara reflete as cores do campo e das roupas coloridas. Trata-se de uma idéia de moderno veiculada pelos elementos videográficos.

O moderno na cidade também nos é apresentada de maneira leve, arejada. Há uma cenografia especial para alguns lugares do centro da cidade. Há o uso do filtro flood (também conhecido como Rembrandt) para a seqüência de cenas noturnas de rua e no Vaudeville criando uma atmosfera de lirismo. Possuindo muitas variantes de suave (mais suave, menos suave) este filtro suaviza a imagem deixando as áreas claras e escura menos duras, a relação claro escuro menos violenta, o contrario dos diálogos que se passam no mundo arcaico do Coronel Totonho.

Além do ambiente claro e suave expressos como próprios ao novo mundo do moderno, a minissérie também veicula para este novo mundo a idéia do mágico e do futuro dinâmico. As seqüências em que aparecem o Theatro Municipal veiculam bem esta idéia utilizando recursos de iluminação que glamourizam a esperada modernidade. Ela tem a sua razão de ser, pois, configuram uma visão de mundo de alguns modernistas como Menotti Del Piccha e de alguns setores da burguesia. Svecenko (1992, pp 112-113) chama atenção para a paisagem urbana retratada por um crítico de artes do jornal "O Estado" que descreve o "uso cenográfico da eletricidade" que cria campos de destaque visual, posições ofuscadas e sombras misteriosas. Seu comentário assinalaria como os faróis dos carros providenciavam focos luminosos móveis que ressaltavam personagens em evidências instantâneas; acelerando a mobilidade de deslocamentos visuais como num filme.

Ora, esta oposição entre o velho e o novo, o passado agrário e o futuro industrializado delineando-se na minissérie é também constitutiva da configuração do moderno. Cabe aqui, no entanto, reproduzir o comentário de Renato Ortiz (2001:189) para quem não houve verdadeiramente uma ruptura com o passado oligárquico e rural e que para quem nós nunca fomos modernos, mesmo em meio das inovações da época. Para ele nossa modernidade não está desvinculada de um passado agrário e colonial. Ele observa: 
A sociedade brasileira do inicio do século era (..) marcada pela contradição tradicional/moderno; seu presente agrário contrastava com o ideal de uma modernidade ainda ausente. $O$ tema foi amplamente tratado pelo movimento modernista. Seus participantes cantavam o cinema, o avião, os bondes elétricos, o jazzband, a industria, procurando por sinais de modernidade presente na sociedade brasileira da década de 1920. $O$ modernismo queria ser um rompimento com o passado tradicional. Vários intérpretes sublinhavam esta dimensão de ruptura. Tristão de Ataide dizia que o movimento frutificou em São Paulo porque aí os artistas experimentavam em seu cotidiano os componentes da vida moderna: "o asfalto, o motor, o rádio, o tumulto, o rumor, a vida ao ar livre, as grandes massas, os grandes efeitos, o cinema transportado para os demais setores estéticos e marcando-os com sua estética de seccionamento, o primado da técnica sobre o natural". A descrição é viva mais desfocada. Ela encobre a existência de uma São Paulo provinciana, mal ajustada ao ideal cultivado pela técnica e pela imagem de velocidade. A imaginação poética não deve obscurecer nosso juizo. O processo de industrialização em São Paulo foi lento na década de 1920, o mesmo pode ser dito do Brasil. Esquece-se, muitas vezes, de que entre nós o modernismo ocorreu sem modernização, o que significa a presença de um hiato entre as intenções do movimento e a própria sociedade que lhe dá sustentação. Nesse sentido, a modernidade não é algo atual, mas uma aspiração, um projeto a ser construido no futuro.

A minissérie apresenta esta oposição entre o passado e o futuro, mas, como um imenso mosaico, também apresenta sutilmente a proposta do grupo de modernistas como Oswald de Andrade e seu grupo que identificavam o modernismo como uma questão nacional. A obra mostra este grupo em vários momentos e vale aqui 
contextualizá-lo com o auxílio de estudos teóricos. Como observa Helena (2003, p.48) o movimento apresentava uma proposta que queria se contrapor a seu passado agrário e tradicional e que passaria pelo rompimento da arte de importação, valorização da cultura popular e por meio da pesquisa do dado popular. Tratava-se de restaurar a dignidade da língua e das manifestações populares para influir na literatura e filtrar o interesse pela "vanguarda européia" nas artes plásticas.

A observação nos instrui sobre o papel do grupo que a minissérie apresenta. Mas como um grande mosaico das imagens de modernidade e modernismo que é apresentado à maneira das colagens, questionamos se a minissérie conduziria a uma efetiva discussão entre a articulação da vanguarda modernista e os rumos que a sociedade brasileira tomaria durante a República Nova e o Estado Novo. Em outras palavras há, em termos da visualidade, a expressão das duas idéias misturadas que não se distinguem: a história linear que rompe com o passado agrário em direção a uma São Paulo moderna e do futuro e, por outro lado, um presente progressista imbricado às singularidades arcaicas do país.

Assim, como um grande mosaico, a minissérie apenas joga as questões e não as resolve. De um lado, dá mostras de enaltecimento de um moderno abstrato e, de outro, do moderno brasileiro singularizado no âmago das contradições brasileiras, à maneira do grupo de Oswald de Andrade. É o caso das imagens da dança no campo em que o grupo se expressa com as cores vivas e tropicais tais como aquelas dos quadros de Tarsila. No entanto, vale observar finalmente que se estas imagens singulares podem marcar uma proposta de identidade para a especificidade do moderno brasileiro, elas se misturam com as imagens do moderno glamourizado e abstrato, viés atualmente comum entre minisséries e filmes que mostram épocas.

Dentro desta discussão temos motivos para supor que a minissérie "Um só Coração" constrói um passado glamourizado que não representa o conteúdo histórico, mas antes uma forma estilizada. Os comentários de Jameson parecem bem plausíveis visto que esta minissérie se coloca na esteira de outras produções contemporâneas, dentro de uma estética do pós-modernismo. Vejamos: 
O esmaecimento do passado, em especial do passado colonial e suas representações, sob as possibilidades tecnológicas e das mídias, torna as épocas anteriores-a palavra época demarcando não mais periodos históricos, mas mentalidades-tão ou mais familiares do que aquilo que chamamos presente. Filmes e novelas sobre os anos 1920 ou os anos 1950, sobre a depressão americana, sobre os anos dourados ou sobre os anos de chumbo brasileiros fazem com que o passado seja recontextualizado, glamorizado e, muitas vezes, sirva de canal não para mostrar uma anterioridade, real ou ficticia, mas para analisar questões contemporâneas: para Jameson, uma pós-nostalgia a consumir o passado na forma de imagens sofisticadas.

Nessas releituras, o passado é glamorizado; os padrões de beleza e os comportamentos sociais dos personagens refletem sensibilidade e problemáticas contemporâneas, e não as questões da época em tela. A isso Jameson denomina de colonização do presente. Para ele "os filmes de nostalgia nunca enfrentam a questão demodée da. representação' do conteúdo histórico e, em vez disso, abordam o 'passado' através da conotação estilística, apresentando a anterioridade através do brilho falso das imagens, e o 'típico dos anos 30 ou dos 50 através das caracterizações da moda. (JAMESON apud GASTAL, 2006, p.112)

À maneira das produções hollywoodianas, pode-se observar, a partir das figurações do moderno e da modernidade, o sentido abstrato e genérico das questões da identidade e da memória de São Paulo. No entanto, se o cenário, como vimos possibilitou uma dissolução da identidade as figurações do figurino têm alguma possibilidade de recriar um "lócus" e uma especificidade para a memória paulistana e brasileira. 


\section{O recurso da intertextualidade no figurino.}

Malcom Bernard (2003, p.238) traz a discussão sobre a questão da representação $\mathrm{x}$ intertextualidade própria à discussão do pós-moderno. Para ele, o uso das palavras "simbolizando" ou "representando" é parte da descrição modernista do objeto moderno. Esta descrição explica o significado do objeto em termos de relações fixas e estáveis como as de identidade de classe e de gênero entre outras. Ao contrário, a descrição do objeto pós-moderno explicaria o significado do objeto sendo produzido intertextualmente. Esta explicaria o sentido de um objeto nos termos das relações do objeto com outros objetos, e do seu lugar em vários diferentes textos ou discursos.

A descrição intertextual como também ensina Hutcheon (1991) enfraquece a História já que relativiza sua existência abstrata e mostra a existência de histórias, narrativas e interpretações, singularizando e contextualizando os dados factuais em situações específicas.

Estas reflexões da teoria pós-moderna são importantes para identificar o tipo de apropriação do moderno e do modernismo que a minissérie, situada em um contexto contemporâneo, apresenta. Teria o figurino funções sinaléticas, representativas ou, ao contrário, intertextuais? Ou seria uma combinação de todos estes elementos?

Nossas primeiras fontes de dados são os croquis dos figurinos da minissérie disponíveis para a exposição "O vestir em São Paulo pela lente de "Um só Coração" realizada na Universidade Anhembi Morumbi em 2004. Examinando o depoimento da curadora da exposição, Claudia Fares, sobre trabalho da figurinista Emilia Duncan vemos ressaltado o trabalho de reinterpretações e citações que percorrem todo o conjunto.

Vejamos:

O que se mostra aqui aos fragmentos, indicios de uma realização que só consolida seu brilho na interação com todos os outros elementos. (...) Mas os figurinos, estes fragmentos, em si mesmos, constituem totalidades nas 
quais estão sintetizados os achados oriundos de um minucioso trabalho de pesquisa, reinterpretações $e$ citações que nos levam a sonhar junto com a figurinista. Da mesma maneira podemos vislumbrar os caminhos escolhidos pela criação diante da falta de referências de imagens-é preciso ressaltar que nossa memória iconográfica relativa à moda é rara e dispersa-, de recursos materiais-não se encontram tecidos $e$ complementos à disposição no comércio_e de tempo.

Diante da falta de referências, o que se faz, segundo a curadora, é tecer um caminho fictício em que os figurinos constituem uma intertextualidade entre si e com os recursos contemporâneos disponíveis. A representação fiel e sinalética da história não seria tão primordial.

No que diz respeito ao figurino da personagem Yolanda Penteado, protagonista da minissérie, pode-se perceber que seu figurino efetivamente retrata mudanças no papel feminino. No entanto, em termos de forma observamos muito mais uma representação do que uma intertextualidade. A intertextualidade existe sim e deve ser sublinhada, porém no caso da personagem Yolanda, não é o princípio geral. Quando dizemos intertextualidade estamos nos referindo não somente à reinterpretação da própria personagem histórica, mas à conexão com outras personagens, tempos históricos ou materiais. Yolanda segue seu tempo e o figurino de Emilia Duncan se esforça em mostrá-la como uma mulher da época. A intertextualidade aqui se resume a estender um pouco mais o alcance do guarda roupa real da personagem em direção a outros figurinos do mesmo tempo histórico. Não há uma ressignificação deste em direção a outros tempos, espaços e materiais. Vejamos um dos relatórios técnicos de figurino que resume isto que estamos propondo:

Yolanda Penteado -Look 13- Anos 20

Vestido em palha de seda azul-céu e azul-piscina.

Inspirado na estilista francesa Madeleine Vionnet (18761975), famosa pelo uso do corte enviesado. Para Emília 
Duncan, Madeleine Vionnet, apesar de não ser citada entre as preferidas de Yolanda Penteado, era totalmente compativel com seu estilo pessoal, pelo design clássico e simultaneamente dinâmico.

Caberá uma discussão a respeito da representatividade ou da intertextualidade no figurino desta personagem que representa $o$ moderno, discussão esta que somente introduzimos aqui. $O$ figurino de Yolanda se dará de maneira representativa e sinalética como princípio, mas, isto não impedirá que algumas vezes apareça também de forma intertextual, trazendo rearticulações com outros materiais e tempos históricos. O figurino de Tarsila do Amaral é visivelmente mais intertextual do que o de Yolanda. Também é colocada como uma mulher à frente de sua época e a sua relação com a os modernistas que se expressam visualmente em ambientes claros e coloridos certamente contribuem para configurações mais ousadas. Vejamos:

Tarsila do Amaral-Look 9-anos 20

Vestido preto e branco, assimétrico em seda com motivos dos anos 70 inspirado no Art-Decô.

Tarsila o Amaral- Look 6-anos 20

Vestido com estamparia geométrica azul. Casaco em plissé cinza. Tecido atual com estamparia geométrica que remete aos anos 20.

Tarsila do Amaral-lookl-anos 20

Vestido em lamê dourado dos anos $70 \mathrm{com}$ informação geométrica que remete aos anos 20 , reciclado no Ateliê da Rede Globo de Televisão. Os anos 70, com sua tendência de moda retro, massifica e industrializa elementos do Art-Decô.

Os figurinos da personagem Tarsila, assim como de outros personagens, têm muito de um material ressignificado de brechós, 
outros tempos e espaços, o que implica numa maior intertextualidade. Assim, ainda que nem todos os figurinos da minissérie sejam produzidos de maneira intertextual tão radical e que a expressão videográfica da narrativa adquira uma certa linearidade com conceitos ligados à representação, há que se considerar a intertextualidade que, como vimos, alguns figurinos têm tendência para evidenciar.

\section{A questão das referências da história}

Um outro paradoxo da teoria pós-moderna que a minissérie apresenta é a questão do registro da história em tempos da tecnologia do virtual. Se por um lado, a minissérie pretende resgatar um passado de São Paulo, com sua memória e identidade por outro lado, a questão da referência de tempo, espaço e lugar é seriamente abalada em função da tecnologia.

Os fatos históricos retratados pela minissérie como representação do real só podem ser vivenciados pelos espectadores através da mediação tecnológica. Há que se refletir sobre como é visto este passado da cidade de São Paulo quando mediado pela imagem eletrônica em função da própria materialidade do suporte. $O$ conceito de representação ficando, portanto, condicionado pelo modo de produção de imagem.

Ora, nas imagens videográficas e do computador o real não é necessariamente uma referência. A exibição dos fatos históricos pode se mesclar com o presente. $O$ real não sendo necessariamente uma referência, as imagens podem se produzir a partir do nada desfazendo a noção de tempo. As imagens eletrônicas são, neste aspecto como espelhos, por onde podemos olhar no monitor em tempo real (FURTADO, 2002, pp 67:69).

Nas imagens fotográficas, por outro lado, ainda existiria uma retenção do tempo e a idéia de que temos delas é a de testemunho, ainda que não seja sempre a partir de algo verdadeiro. Neste sentido, o jogo com fotografias antigas da cidade de São Paulo nas vinhetas de.abertura talvez sugira uma esperança de que o referente, o dado histórico, ainda prevaleça em meio à tecnologia digital. As vinhetas foram feitas a partir de fotografias antigas e tratadas digitalmente 
pelo computador: seus elementos foram alterados e animados muitas vezes em planos diferentes. Pode-se perceber como os diferentes elementos que compõem uma mesma foto são destacados criando uma falsa impressão de profundidade já que se movimentam em velocidades diferentes. A vinheta faz uso da fotografia como referência, mas como esta sendo trabalhada pelo computador transforma-se em uma imagem virtual, o que relativiza a própria referência. Não deixa de haver um certo paradoxo nesta representação da história.

Quanto aos efeitos de passagem (fade in/fade out/fusões) pode-se supor que a opção por estes efeitos tradicionais (ao invés de efeitos digitais como página virando etc) foram usados para manter um clima de época. Aqui também supomos que houve uma busca pela referência concreta do dado histórico. Na década de 20 , época em que a minissérie é ambientada com mais ênfase, o cinema já existia e esse tipo de recurso já era amplamente utilizado, o espectador havia apreendido novas formas visuais e cognitivas para a representação da passagem tempo/espaço.

Com estas aproximações e distanciamentos do referente, a minissérie oscilaria entre se tornar uma âncora do passado com tempo e espaço e lugar determinados e uma abstração, abstração esta proporcionado pelo virtual, o que implicaria em uma certa "desreferencialização".

\section{Considerações Finais}

A minissérie "Um Só Coração", ao relembrar a história de São Paulo se integra a um dos fenômenos culturais e políticos mais surpreendente dos anos recentes e que, segundo Huyssen (2000, p.9), se caracterizaria como uma volta ao passado numa estratégia de reviver memórias nacionais enquanto práticas atuais da memória. Esse fenômeno expressaria uma volta ao passado contrastando totalmente com o privilégio dado ao futuro, que como observa o autor, tanto caracterizou as primeiras décadas da modernidade do século $\mathrm{XX}$. 
No caso do movimento dos modernistas brasileiros, ao contrário, vimos que pelo menos uma parte dele (Oswald e seu grupo), não buscaria o futuro rompendo com o passado, mas antes o que denominavam como uma proposta de antropofagia. Do ponto de vista da expressão dos recursos estéticos articulados nesta minissérie contemporânea, nosso ângulo privilegiado para estudo, observamos algumas tentativas desta apropriação para constituir uma singularidade brasileira, seja pela intertextualidade dos figurinos ou de alguns cenários. Mas a representação abstrata, a linearidade da narrativa à maneira das telenovelas (onde a discussão das questões da modernidade e do modernismo em São Paulo são, em grande parte, o pano de fundo para os enlaces amorosos do par central) e a glomourização da época enfraquecem a memória e a identidade de São Paulo. Certamente existiriam outras maneiras de pensar a identidade da memória e de uma brasilidade que poderiam, apesar (ou com) todas estas questões (some-se ainda os problemas do enfraquecimento da história no suporte digital) resolver-se muito bem. Parece-nos que este seria o caso da minissérie "Hoje é Dia de Maria", minissérie discutida no XV encontro anual da Associação Nacional dos Programas de Pós-Gruação em Comunicação(COMPÓS) por Renato Cordeiro Gomes no GT Cultura das Mídias.

\section{Bibliografia}

BARNARD, M. 2003. Moda e Comunicação. Rio de Janeiro:Rocco

GOMES, R.C.2006. "Matrizes Culturais e Formatos Industriais: uma série brasileira de televisão. In: Anais do XV encontro anual da Associação Nacional de Pós-Graduação em Comunicação -COMPÓS. Bauru

FURTADO, B. 2002. Imagens eletrônicas e paisagem urbana: intervenções espaço-temporais no mundo da vida cotidiana. Rio de Janeiro:Relume Dumará ; Fortaleza: Secretaria da Cultura e Desporto.

GASTAL, S. 2006. Alegorias Urbanas: o passado como subterfúgio. Campinas: Papirus. 
GUMBRECHT, H. U.1998. Corpo e forma: ensaios para uma critica não hermenêutica. Rio de Janeiro: Ed UERJ.

HELENA, L. 2003. Modernismo Brasileiro e Vanguarda, São Paulo:Editora Ática.

HUTCHEON, L. 1991. Poética do pós modernismo. História. Teoria. Ficção. Rio de Janeiro: Imago.

HUYSSEN, A. 2000. Seduzidos pela memória: arquitetura, monumentos, mídia. Rio de Janeiro: Aeroplano.

NACIF, M. C. V. 2002 O figurino e a questão da representação do personagem. In: I Simpósio de Laboratório de Representação Social - LARS, Rio de Janeiro: PUC

ORTIZ, R. J. P.2001. Sociedade e cultura In: SACHS, I; WILHEIM, J. e PINHEIRO, P. S. (orgs.),. Brasil: um século de transformações. São Paulo:Companhia das Letras.

PALOTTINI, R. 1998. Dramaturgia de televisão. São Paulo:Editora Moderna.PAVIS, Patrice. Dicionário de Teatro. Ed. Perspectiva, 1999.

SEVCENKO, Nicolau. Orfeu extático na metrópole; São Paulo, sociedade e cultura nos frementes anos 20. São Paulo; Companhia das Letras, 1992.

TV Globo, São Paulo através da minissérie Um só Coração. São Paulo, Editora Globo, 2004.

VILAÇA, Nízia. "Um só coração: o modernismo na cultura eletrônica" in Fashion Theory-A Revista de Moda, Corpo e Cultura vol3, Número 2, junho 2004/Berg 2004 e Editora Anhembi Morumbi. 